\title{
Clostridium villosum sp. nov. from Subcutaneous Abscesses in Cats
}

\author{
DARIA N. LOVE, R. F. JONES, AND MARILYN BAILEY \\ Department of Veterinary Pathology, Sydney University, New South Wales 2006, Australia
}

Clostridium villosum sp. nov., isolated from subcutaneous abscesses of cats, is an obligately anaerobic, rod-shaped, sporeforming, monmotile organism which is gram positive in its early stages of growth and gram negative after 18 to $24 \mathrm{~h}$. All strains of this species produce acetic, isobutyric, butyric, isovaleric, lactic, methylmalonic, and succinic acids from cooked meat-carbohydrate and peptone-yeast extract cultures supplemented with $5 \%$ horse serum. All of the strains produce ammonia and liquefy gelatin weakly but do not ferment acids or react in any other biochemical tests performed. The pattern of volatile acids produced, the lack of biochemical activity, the colonial morphology, and the late spore production distinguish C. villosum from other Clostridium species so far described. The type strain of C. villosum is VSB 3349; a culture of this strain has been deposited in the National Collection of Type Cultures under the number 11220.

From June to October 1978 we isolated from subcutaneous "fight wound" abscesses in cats 11 strains of an organism which does not appear to have been described previously. The organisms appeared in smears from purulent material as long, filamentous, gram-negative or gram-variable, rod-shaped bacteria. No spores were seen in the pus smears, but some of the rods appeared barred with nonstaining areas at intervals along the filaments. Purulent material which contained these morphological forms yielded an isolate with a distinctive colonial appearance.

This paper describes the characteristics of the above-mentioned organism, for which we propose the name Clostridium villosum sp. nov. (vil. los'um. L. adj. hairy, shaggy, rough haired). The type strain of $C$. villosum is Veterinary Pathology and Bacteriology Laboratory (VPB) 3349 (National Collection of Type Cultures strain 11220 ).

\section{MATERIALS AND METHODS}

Bacterial strains. The 11 strains studied (VPB) strains 523, 524, 3322, 3326, 3339, 3342, 3344, 3348, 3349,3358 , and 3359 ) were isolated from 11 cats, each with a solitary closed subcutaneous fight wound abscess. The organisms were part of a mixed flora of anaerobic and facultatively anaerobic bacteria found in these abscesses. Cultures of these strains were freeze-dried in skimmed milk after preliminary characterization; subsequently the cultures were revived and then fully characterized in parallel.

Culture media and methods. The organisms were isolated and grown initially on sheep blood agar plates and brain heart infusion agar plates (1), which were poured on the day of use, inoculated, and incubated anaerobically in a GasPak anaerobic system at $37^{\circ} \mathrm{C}$.
Pure cultures of the isolates were grown in cooked meat plus peptic digest of meat (BVF) broth (4) (CMM) or cooked meat plus BVF broth supplemented with $0.4 \%$ glucose, $0.1 \%$ cellobiose, $0.1 \%$ maltose, and $0.1 \%$ starch (CMC). The basal media for fermentation studies were those of Holdeman et al. (1), and the fermentation of carbohydrates was determined by measuring after 5 days the $\mathrm{pH}$ of the cultures with carbohydrate and comparing it with the $\mathrm{pH}$ of the basal medium without carbohydrate incubated for the same length of time. For all biochemical tests, the liquid media except CMM and CMC were supplemented with $5 \%$ horse serum. For the biochemical tests, either GasPak jars in which catalysts had been changed after use and rejuvenated by heating at $160^{\circ} \mathrm{C}$ for $2 \mathrm{~h}$ or prereduced media (1) were used. Tubes of the latter were gassed with oxygen-free carbon dioxide at the time of inoculation.

The reagents and methods described previously (1) were used for the following tests: nitrate reduction; lecithinase, lipase, catalase, ammonia, and acetylmethylcarbinol production; esculin hydrolysis; and indole production in CMM. The medium for gelatin liquefaction was VF gelatin (BVF broth, $100 \mathrm{ml}$; glucose, 0.1 $\mathrm{g}$; gelatin, $12 \mathrm{~g}$; cysteine- $\mathrm{HCl}, 0.05 \mathrm{~g}$; and vitamin $\mathrm{K}-$ heme solution, $1 \mathrm{ml}[1]$; the gelatin was clarified with beaten egg white and sterilized at $121^{\circ} \mathrm{C}$ for $15 \mathrm{~min}$ ).

Fatty acids were extracted from CMC, peptoneyeast extract broth containing $5 \%$ horse serum (SPY), SPY-glucose, SPY-threonine, SPY-pyruvate, and SPY-lactate cultures as described previously (1) and were detected by gas-liquid chromatography on a Hewlett-Packard model 5830A gas chromatograph. A glass column $160 \mathrm{~cm}$ long and with an internal diameter of $2 \mathrm{~mm}$ was packed with $10 \%$ AT1200 plus $1 \%$ $\mathrm{H}_{3} \mathrm{PO}_{4}$ on Chromosorb W-AW (80/100 mesh [AT$1200])$ was used. The carrier gas was nitrogen at a flow rate of $30 \mathrm{ml} / \mathrm{min}$, the oven temperature was $115^{\circ} \mathrm{C}$, and the flame ionizer detector was run at $225^{\circ} \mathrm{C}$. A Hewlett-Packard model 7671A automatic sampler was 
used for all injections. The machine was computer programmed to quantitate the products of fermentation.

Gram stains were made on young cultures (8 to 12 $h$ old) from cooked meat medium without carbohydrate and from blood agar to determine whether grampositive cells were present. Young cultures were fixed with $2 \%$ glutaraldehyde in $0.1 \mathrm{M}$ cacodylate buffer, postfixed in $2 \%$ uranyl acetate, embedded, sectioned, and examined in a transmission electron microscope to determine cell wall structure. Cultures grown on blood agar plates and CMC slants incubated anaerobically for up to 3 weeks were Gram stained and, if spores or barred gram-negative cells were present, samples were emulsified in CMC, and each was heated by submerging in a water bath at $80^{\circ} \mathrm{C}$ for $10 \mathrm{~min}$ or $90^{\circ} \mathrm{C}$ for $5 \mathrm{~min}$. The heated broth was then inoculated into fresh $\mathrm{CMC}$ and incubated at $37^{\circ} \mathrm{C}$ to detect heatresistant cells. Usually two subcultures at 3-day intervals were necessary to regain good growth of organisms. Samples from 3-week-old CMC slants were fixed in $2 \%$ glutaraldehyde in $0.1 \mathrm{M}$ cacodylate buffer, postfixed in $2 \%$ uranyl acetate, embedded, sectioned, and then examined in a transmission electron microscope for spore formation and characteristics.

Repeated subcultures to blood plates and CMC slants incubated aerobically or in a candle extinction jar were performed to determine the oxygen relationships of the organism. Growth at the bottom of tubes of tryptose phosphate medium (yeast extract, $1 \mathrm{~g}$; tryptose, $20 \mathrm{~g}$; NaCl, $5 \mathrm{~g}$; glucose, $1 \mathrm{~g}$; agar, $1 \mathrm{~g}$; and $\mathrm{Na}_{2} \mathrm{PO}_{4} \cdot 12 \mathrm{H}_{2} \mathrm{O}, 2.5 \mathrm{~g}$; all dissolved in 1 liter of water and sterilized at $121^{\circ} \mathrm{C}$ for $15 \mathrm{~min}$ ) and movement away from a central inoculation site in such tubes were used to aid determination of motility, spore formation, and anaerobiosis. Cultures at various stages of growth in $\mathrm{CMC}$ were examined for motility in wet preparations and were examined for flagella by negative staining with $2 \%$ phosphotungstic acid and viewing in a transmission electron microscope. The broth disk test of Williams and Thiel (5) was used to determine susceptibility to antimicrobial agents.

\section{RESULTS AND DISCUSSION}

Morphology and Gram staining. All of the strains studied had similar morphology and Gram stain reactions. Cells were rod shaped with parallel sides and rounded ends and measured 0.6 by 4.0 to $6.0 \mu \mathrm{m}$. Filaments reaching 24 to 30 $\mu \mathrm{m}$ in length were common in cultures more than 24 to $48 \mathrm{~h}$ old. Thin-section electron microscopy showed that the structure of the cell wall and the mode of division were consistent with gram-positive organisms and that numerous mesosomes were produced. Individual cells retained the Gram stain for up to 18 to $24 \mathrm{~h}$ in broth culture or on an agar surface but became gram variable or gram negative after this time. By 7 days most of the cells showed gram-negative staining, with nonstaining gaps at intervals along the cell, thus giving the organisms a barred or beaded appearance. Electron microscopy showed many large cytoplasmic vacuoles in the cells.

Colonial characteristics. Agar colonies of all of the strains were basically similar. Surface colonies on solid media measured $0.5 \mathrm{~mm}$ at 24 h (Fig. 1) and increased to approximately $5 \mathrm{~mm}$ by 3 days. Mature colonies were differentiated into central and peripheral portions (Fig. 2). The central portion was raised convex or domeshaped, rough, dull, and whitish to yellowish in color, whereas the peripheral portion varied among strains but had a greater or lesser extent of rhizoid or fimbriate edge (Fig. 2). All colonies were strongly adherent to the underlying medium, and colonies with less peripheral portions had their central zones more deeply indented into the agar. No hemolysis was noted on blood agar plates. The colonies were very difficult to emulsify, and rigorous trituration was required to obtain even a granular suspension. Deep stab colonies appeared like whisps of wool or cotton with a dense granular center. There was no

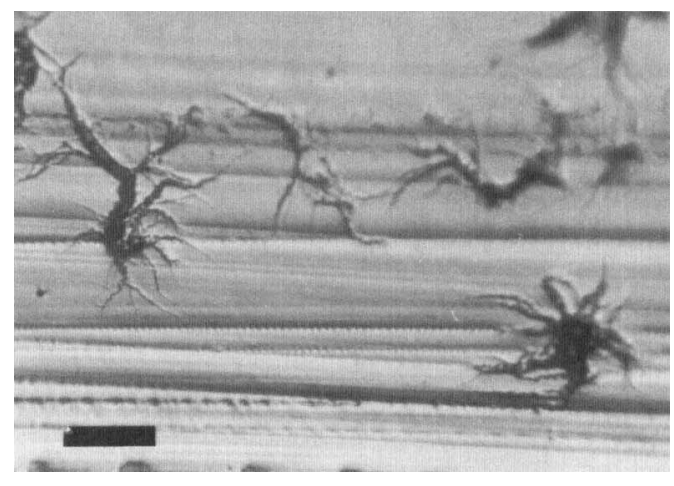

FIG. 1. Surface colony on blood agar at $24 h$. Bar $=1 \mathrm{~mm}$.

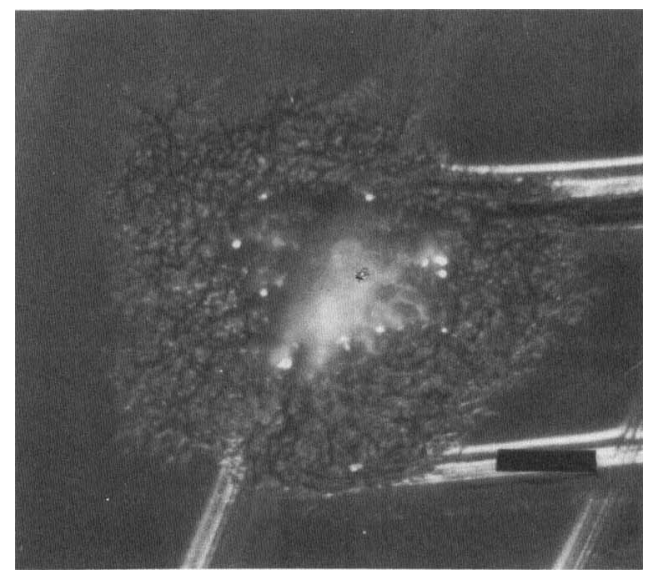

FIG. 2. Surface colony on blood agar at 3 days. $B a r=1 \mathrm{~mm}$. 
growth on the surface of blood agar plates or CMC slants incubated aerobically or in a candle extinction jar.

Cultural characteristics. Organisms would not grow in prereduced or conventionally prepared, anaerobically incubated peptone-yeast extract without the addition of $5 \%$ horse serum. Tween 80 and formate-fumerate supplementation (1) did not stimulate growth. Cultures in SPY showed slight turbidity with membranous or clumpy growth (Fig. 3). Strains grew well in $\mathrm{CMC}$ whether the medium was (i) prereduced, (ii) conventionally prepared and incubated anaerobically, or (iii) steamed and cooled before inoculation and incubation. In CMC the organisms formed a delicate membrane near the surface of the broth, and throughout this membrane the bacteria clumped and appeared as discrete colonies resembling those formed in agar stabs. Late in growth, the membrane structure collapsed and settled into and around the meat particles (Fig. 4).

Motility. Extensive observations of broth cultures were made to try to detect motility. Motility was not observed in cultures varying from a few hours to 10 days of age when examined with a light microscope, and electron microscope examination of negatively stained preparations of these cultures failed to reveal flagella. Organisms seeded from CMC into the center of deep tubes

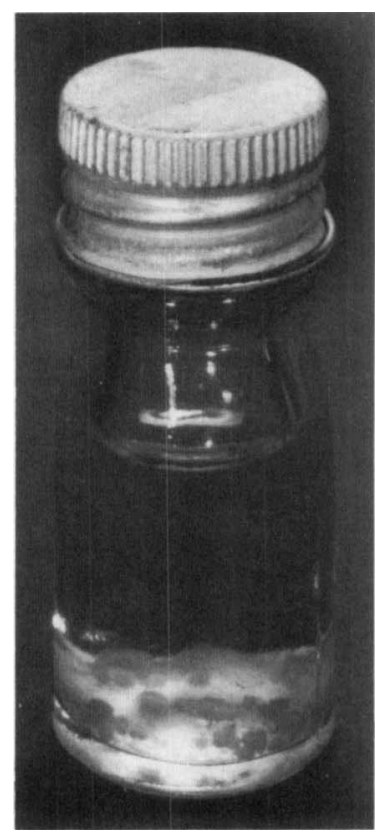

Fig. 3. Strain VPB 3349 grown anaerobically for 5 days in SPY. Note clear supernatant and colonylike deposit.

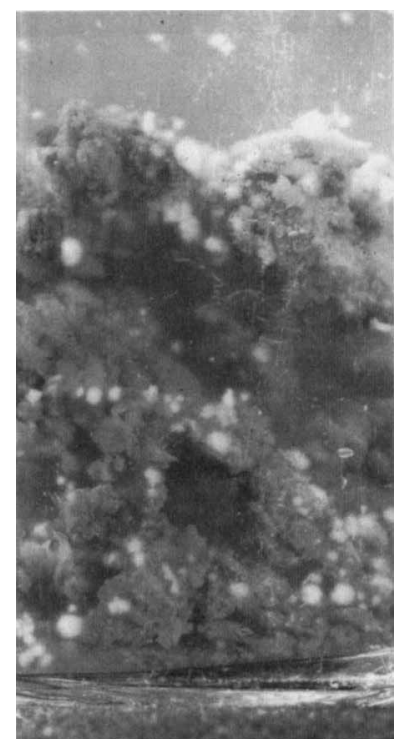

FIG. 4. Strain VPB 3339 grown for 5 days in CMC. Note the colony-like clumps of bacteria scattered through the meat particles and the ropy membrane settled on their upper surface.

of the semisolid tryptose phosphate medium failed also to provide evidence of motility in any of the strains. These rigorous observations were thought necessary, as the colonial appearance of the organisms suggested that they could be motile.

Spore formation. Spores were single, oval, and subterminal and caused a slight distention of the sporangium. Immature spores were smaller, retained the Gram stain, and appeared as small, bluish spots in the otherwise gramnegative rods. When the organisms were isolated, spores were not detected, possibly because the cultures were not incubated long enough. However, for all of the strains, anaerobically incubated $\mathrm{CMC}$ slant cultures were heat resistant $\left(10 \mathrm{~min}\right.$ at $80^{\circ} \mathrm{C} ; 5 \mathrm{~min}$ at $\left.90^{\circ} \mathrm{C}\right)$ after 2 weeks of incubation. Cells of these cultures were gram negative and had barred staining. Heat-resistant spores of strains 523, 3349, and 3857 were also produced on blood agar plates incubated anaerobically for 3 weeks. Heat-resistant cells were not detected in any strain grown for up to 3 weeks in either CMC or tryptose phosphate medium.

Biochemical reactions. All of the strains liquefied gelatin weakly, and ammonia was produced in CMM and SPY. None of the strains fermented any of the carbohydrates tested (esculin, fructose, glucose, lactose, maltose, mannitol, mannose, melibiose, ribose, sucrose, xylose), as determined by $\mathrm{pH}$ measurement. None 
TABLE 1. Mean amounts of major volatile fatty acids produced in various media by the 11 strains studied

\begin{tabular}{|c|c|c|c|c|c|c|c|c|c|}
\hline \multirow[b]{2}{*}{ Acid produced } & \multicolumn{9}{|c|}{ Mean meq of acid produced per $100 \mathrm{ml}$ of culture medium } \\
\hline & $\mathrm{CMC}^{a}$ & $\mathrm{CMC}^{b}$ & PR CMC & PR SPYc & $\begin{array}{l}\text { PR SPY. } \\
\text { glucose }^{c}\end{array}$ & SPY & $\begin{array}{c}\text { SPY- } \\
\text { threonine }\end{array}$ & $\begin{array}{c}\text { SPY- } \\
\text { pyruvate }\end{array}$ & $\begin{array}{l}\text { SPY- } \\
\text { lactate }\end{array}$ \\
\hline Acetic & 1.62 & 0.51 & $0.5 \mathrm{i}$ & 0.31 & 0.40 & 0.51 & 1.08 & 0.76 & 0.51 \\
\hline Isobutyric & 0.34 & 0.34 & 0.16 & 0.07 & 0.06 & 0.24 & 0.31 & 0.19 & 0.13 \\
\hline Butyric & 3.23 & 4.23 & 2.04 & 1.04 & 0.88 & 1.99 & 3.33 & 3.72 & 2.01 \\
\hline Isovaleric & 0.76 & 1.05 & 0.46 & 0.18 & 0.16 & 0.41 & 0.54 & 0.38 & 0.34 \\
\hline
\end{tabular}

${ }^{a}$ Cultures incubated anaerobically.

${ }^{b}$ Cultures incubated aerobically after boiling and cooling medium before inoculation.

Cultures prepared and incubated under prereduced (PR) conditions.

of the strains gave positive reactions in any of the other biochemical tests performed.

Fermentation products. Strains were grown for 2 days in CMC and for 5 days in SPY. The major fermentation acids detected from CMC cultures are listed in Table 1. Trace amounts of lactic, succinic, and methylmalonic acids were detected. As reflected in Table 1, the organisms grew better in CMC than in SPY media. However, organisms grew better in CMC incubated in GasPak jars or aerobically than in prereduced CMC. It seems, therefore, that CMC is beneficial with respect to both nutrition and $\mathrm{pH}$. The fermentation products resulting from growth in SPY, SPY-glucose, SPY-threonine, SPY-pyruvate, and SPY-lactate can be seen in Table 1. Threonine was not converted to propionate, and lactate was not utilized, but greater amounts of butyric acid were produced in cultures which contained pyruvic acid than in those which did not. All strains produced fermentation products from SPY-based medium, but, with the exception of SPY-threonine, the amounts of products produced were considerably lower than those from CMC.

Resistance to antimicrobial agents. All strains were susceptible to penicillin $(2 \mathrm{U} / \mathrm{ml})$, amoxycillin $(2.5 \mu \mathrm{g} / \mathrm{ml})$, carbenicillin $(100 \mu \mathrm{g} /$ $\mathrm{ml})$, doxycycline $(6 \mu \mathrm{g} / \mathrm{ml})$, chloramphenicol (12 $\mu \mathrm{g} / \mathrm{ml})$, and erythromycin $(3 \mu \mathrm{g} / \mathrm{ml})$.

Distinguishing characteristics. The characteristics of C. villosum do not conform to those of any of the published descriptions of other members of the genus Clostridium (3), and no reference to this sort of organism could be found in a thorough search of the current literature.

Spores are not readily detected in this species, and the cells are usually observed to be gramnegative rods. It is possible, however, to distinguish it from gram-negative, rod-shaped species by its gram-positive or gram-variable reaction in young cells, by its strictly anaerobic growth, and by its distinctive colonial appearance. However, its fermentation products suggest that it may be confused with some members of the genus Bacteroides (2), but the fact that it does not produce propionic acid should help distinguish it from members of that genus.

Pathogenic significance. The organism described here was found as one of a number of anaerobic species present in each abscess examined. It was always present in large numbers, but it has yet to be determined whether these bacteria alone are able to produce disease. The indication is that the organism is present as part of the oral flora of cats and contributes to the purulent disease after gaining entry, along with other anaerobes, into an unusual site. It is perhaps significant that we have also isolated strains identical to those reported here from the pyothorax in cats. In that site, it is likely that the organism is pathogenic; and in the thoracic lesions it was the predominant isolate.

\section{ACKNOWLEDGMENTS}

We gratefully acknowledge the skilled technical assistance of A. M. Whittington, who prepared all media, and R. G. Wright for his enthusiastic assistance in electron microscopy.

This research was supported by a University of Sydney Research Grant.

\section{REPRINT REQUESTS}

Address reprint requests to: Dr. Daria Love, Department of Veterinary Pathology, Sydney University, N.S.W. 2006, Australia.

\section{LITERATURE CITED}

1. Holdeman, L. V., E. P. Cato, and W. E. C. Moore (ed.). 1977. Anaerobe laboratory manual, 4th ed. Virginia Polytechnic Institute and State University, Blacksburg.

2. Holdeman, L. V., and W. E. C. Moore. 1974. Genus I. Bacteroides Castellani and Chalmers 1919,959 , p. 385404. In R. E. Buchanan and N. E. Gibbons (ed.), Bergey's manual of determinative bacteriology, 8 th ed. The Williams and Wilkins Co., Baltimore.

3. Smith, L. DS., and G. Hobbs. 1974. Genus III. Clostrid. ium Prazmowski 1880, 23, p. 551-572. In R. E. Buchanan and N. E. Gibbons (ed.), Bergey's manual of determinative bacteriology, 8th ed. The Williams and Wilkins Co., Baltimore.

4. Turner, A. W., A. D. Campbell, and A. T. Dick. 1935. Recent work on pleuro-pneumonia contagiosa boum in North Queensland. Aust. Vet. J. 11:63-70.

5. Wilkins, T. D., and T. Thiel. 1973. Modified broth-disk method for testing the antibiotic susceptibility of anaerobic bacteria. Antimicrob. Agents Chemother. 3: $350-356$. 